\title{
Right bundle-branch block and left axis deviation in acute myocardial infarction
}

Sir:

The article by Roos and Dunning (British Heart fournal, 1970, 32, 847) deserves some comments.

The authors interpret the right axis deviation appearing in Case II as a manifestation of block in the posterior division of the left branch. This conduction disturbance is, in fact, a rare cause of right axis deviation (Rosenbaum, Elizari, and Lazzari, 1968) and, as Castellanos et al. (1970) pointed out, the condition cannot be diagnosed in the presence of other causes of abnormal right axis deviation, namely, extensive loss of lateral electrical forces, as seems to be the case in this particular patient (QS pattern in DI and aVL and appearance of small $Q$ waves in $V_{5}-6$ ).

In the presence of block in the posterior division of the left branch, excitation will proceed through the intact anterior (and superior) division in an anterosuperior and slightly leftward direction. The initial vectors will have an identical orientation: a q wave will be recorded in $D_{2}, D_{3}$, and $\mathrm{aVF}$, and an $\mathrm{r}$ wave will appear in Dr and aVL, illustrating a clockwise pattern of rotation of the frontal plane QRS loop. In the case under discussion, such peculiar reorientation of the initial vectors cannot be seen. A small $q$ wave, absent in the first tracing, appears in D2 and aVF of the second tracing. However, the absence of a $q$ wave in $D_{3}$ and of small $r$ waves in Dr and aVL means that the initial vectors have a frankly rightward and slightly superior orientation, the QRS loop rotating counterclockwise in the frontal plane. This fact is hard to understand in the presence of block in the posterior division of the left branch and can otherwise be assigned to the loss of lateral electrical forces.

The above-mentioned reorientation of the initial vectors is of the utmost importance for the identification of block in the posterior division, as stressed by Cerqueira-Gomes (1970) and others (Castellanos et al., 1970), and attention to it will prevent 'overdiagnosis'.

\section{ABREU E LIMA University Hospital Porto, Portugal}

We showed Dr. Abreu e Lima's letter to Drs. Roos and Dunning, who commented as follows:

Dr. C. de Abreu is, of course, right in stating that the diagnosis of block in the posterior division of the left bundle-branch is difficult in the presence of extensive lateral infarction. Coexistence of both conditions, however, is not excluded.

As we mentioned in our article, recordings of the electrogram of the His bundle are needed to establish with certainty the diagnosis of bilateral bundle-branch block. Without these, as in our patients, the diagnosis is based on other, supportive, evidence.

Castellanos et al. (1970) stress the fact that a double conduction disturbance is strongly suggested in patients with right bundle-branch block and right axis deviation, by the presence of a prolonged PR interval and the occurrence of the Mobitz type II block.

Our patient had a prolonged PR interval and periods of sudden complete AV block, without previous progressive lengthening of the PR interval, apparently due to sudden trifascicular block. It seems logical that the ventricular activation changes in the presence of extensive anterolateral and septal infarction and that, as a consequence, the electrocardiogram does not meet all the original criteria of Rosenbaum. In fact, the loss of lateral electrical forces explains the lack of clockwise rotation in the frontal plane. Thus, we believe our interpretation to be correct and not to be based on 'overdiagnosis'.

J. C. ROOS

A. J. DUNNING Binnengasthuis, Universiteitskliniek
voor Inwendige Ziekten, Amsterdam-C,
The Netherlands

\section{References}

Castellanos, A., Jr., Maytin, O., Arcebal, A. G., and Lemberg, L. (1970). Significance of complete right bundlebranch block with right axis deviation in absence of right ventricular hypertrophy. British Heart fournal, 32, 85.

Cerqueira-Gomes, M. (1970). Novas ideias sobré a activação septal. Boletim da Sociedade Portuguesa de Cardiologia,
8, 61 . 8, 6r.

Rosenbaum, M. B., Elizari, M. V. and Lazzari, J. O., (1968). 